\title{
GAMBARAN KEBUTUHAN ORANGTUA DENGAN BAYI YANG SAKIT KRITIS DI RSUD PROF.DR. MARGONO SOEKARJO PURWOKERTO
}

\author{
Adiratna Sekar Siwi ${ }^{1}$ \\ ${ }^{1}$ Program Studi Sarjana Keperawatan, Universitas Harapan Bangsa \\ adiratnasekarsiwi@uhb.ac.id
}

\begin{abstract}
ABSTRAK
Pelayanan yang holistik, perawat harus melibatkan orangtua dalam rencana perawatan bayinya. Perawat perlu mengetahui kebutuhan yang diperlukan oleh orang tua. Kebutuhan setiap orangtua berbeda-beda karena banyak faktor yang memengaruhinya. Kebutuhan orangtua meliputi kebutuhan informasi, kepastian, kedekatan, kenyamanan serta dukungan. Apabila kebutuhan orangtua dapat terkaji dengan baik maka perawat dapat memberikan intervensi yang tepat. Terpenuhinya kebutuhan orangtua dapat meningkatkan kualitas pelayanan serta membantu mengatasi masalah psikososial.

Penelitian ini merupakan studi deskriptif dengan pendekatan cross sectional. Penelitian ini melibatkan 70 responden. Teknik sampling yang digunakan dalam penelitian ini adalah non probability sampling, dengan consecutive sampling. Pengambilan data dilaksanakan pada bulan Juni- Juli 2016 di RSUD Prof. Dr. Margono Soekarjo Purwokerto. Instrumen dalam penelitian ini adalah kuesioner NFNI (NICU Family Needs Inventory). Data yang diperoleh dianalisis menggunakan analisis univariat dan disajikan dalam bentuk rerata nilai masing-masing kebutuhan. Hasil penelitian ini menunjukkan bahwa kebutuhan orangtua dengan bayi sakit kritis di NICU adalah kebutuhan terhadap kedekatan (mean 3.54), kepastian (mean 3.49), kenyamanan (mean 3.25), informasi (mean 3.24) dan kebutuhan yang terakhir adalah adalah kebutuhan terhadap dukungan (mean 3.15). Kebutuhan yang paling dibutuhkan oleh orangtua adalah kebutuhan terhadap kedekatan. Oleh karenanya, perlu adanya kebijakan rumah sakit untuk memberikan kesempatan kepada orang tua menunggu bayinya lebih lama.
\end{abstract}

Kata Kunci: Kebutuhan orangtua, Neonatal Intensive care,

\begin{abstract}
Patient's parent is an essential part of holistically care treatment, especially when the patients are still too young to responsible for their own. Nurse have to understand regarding parents need to deliver high quality care for patients and their family. Parents' needs during accompanying their children could be very specific and unique. The knowledge regarding this issue is crucial to increase the quality of care and prevent parents' psychological problem.

This is a descriptive study with cross sectional approach. Total sample in this study are respondent who are chosen by using consecutive sampling. The NICU Family Needs Inventory (NFNI) was used in this study.

This study shows that the parents' needs during accompanying their children in critical care setting are need for closeness with their children, Certainty regarding patient condition, comfort, information, and the needs of support.
\end{abstract}

Keywords: Parents' needs, Neonatal Intensive Care Unit 
Viva Medika: Jurnal Kesehatan, Kebidanan, dan Keperawatan, 11 (02), Maret 2019

Adiratna Sekar Siwi (Gambaran Kebutuhan Orangtua Dengan Bayi Yang Sakit kritis di RSUD

Prof.dr. Margono Soekarjo Purwokerto)

\section{PENDAHULUAN}

Pelayanan yang holistik, perawat harus melibatkan orangtua dalam rencana perawatan bayinya. Perawat perlu mengetahui kebutuhan yang diperlukan oleh orang tua dan diharapkan perawat mampu menyusun intervensi untuk memenuhi kebutuhan orang tua bayi. Pelayanan keperawatan saat ini menganggap orangtua menjadi mitra atau klien yang turut menentukan kebutuhan bayi serta pemenuhan kebutuhan keluarga (Supartini, 2004).

Kebutuhan setiap orangtua berbeda-beda karena banyak faktor yang memengaruhi kebutuhan tersebut. Menurut Ward (2001), secara umum kebutuhan orangtua terbagi menjadi 5 meliputi kebutuhan informasi, kepastian, kedekatan, kenyamanan serta dukungan. Peran perawat selain memberikan asuhan keperawatan kepada bayi, juga harus memperhatikan kebutuhan orangtua. Dalam pelayanan keperawatan, orangtua merupakan salah satu bagian atau mitra dari perawat. Apabila kebutuhan orangtua dapat terkaji dan teridentifikasi dengan baik maka perawat dapat memberikan intervensi yang tepat sesuai dengan kebutuhan orangtua. Terpenuhinya kebutuhan orangtua dapat meningkatkan kualitas pelayanan serta membantu mengatasi masalah psikososial orangtua.

Penelitian yang dilakukan oleh Hendrawati (2015) bahwa orangtua membutuhkan informasi terhadap perkembangan kondisi dan tindakan yang dilakukan terhadap bayinya secara jujur, jelas dan rutin, jaminan bayinya mendapatkan perawatan yang terbaik serta kedekatan dengan bayinya. Pemberian informasi yang diberikan oleh perawat kepada orangtua mengenai kondisi kesehatan bayi, akan membantu orangtua mengetahui kebutuhan kesehatan bayi dan bisa menurunkan kecemasan orangtua (Fenwick et al, 2001; Mok \& Leung, 2006; Orapiriyakul et al, 2007 dalam Kearvell \& Grant, 2008). Jika orangtua mendapatkan informasi dan bisa terlibat dalam perawatan bayinya di NICU maka orangtua merasakan kenyamanan dan terjalin hubungan 
Viva Medika: Jurnal Kesehatan, Kebidanan, dan Keperawatan, 11 (02), Maret 2019

Adiratna Sekar Siwi (Gambaran Kebutuhan Orangtua Dengan Bayi Yang Sakit kritis di RSUD

Prof.dr. Margono Soekarjo Purwokerto)

yang baik dibangun antara perawat, orangtua serta bayinya (Fenwick, Braclay \& Schmied, 2008).

Penelitian lain oleh Sikorova \& Kucova (2012) tentang identifikasi kebutuhan orangtua dengan bayi yang dirawat di ruang NICU di Ostrava, Czech Republic menunjukkan hasil bahwa orangtua sangat membutuhkan dukungan dari perawat. Orangtua membutuhkan caring dari perawat untuk berrespon dengan baik terhadap pertanyaan dari orangtua dan melibatkan orang tua dalam merawat bayinya yang sedang sakit. Apabila orangtua tidak dilibatkan dalam perawatan bayinya, maka dapat menimbulkan stres yang tinggi akibat berpisah dengan bayinya, merasa tidak berdaya dan tidak mampu melindungi bayinya dari prosedur perawatan yang menyakitkan dan ketidakmampuan untuk menyusui bayinya secara langsung. Ibu dapat mengatasi masalah-masalah yang dihadapi karena mendapatkan dukungan dari tenaga kesehatan serta hubungan sosial (Lee, 2008).
Penelitian berbeda yang dilakukan oleh Mundy (2010), bahwa kebutuhan terhadap kepastian merupakan kebutuhan yang paling penting bagi orangtua. Orangtua menginginkan perawat selalu menghubungi mengenai perubahan kondisi bayinya, kepastian bahwa bayinya mendapatkan perawatan yang terbaik. Orangtua juga membutuhkan ketenangan dan kenyamanan dari perawat, yang memberikan edukasi, dukungan emosional, dorongan semangat serta pengalamannya selama merawat bayi di NICU (Johnson, 2007 dalam Kearvell \& Grant, 2008). Upaya tersebut dapat memberikan kekuatan dan pengetahuan kepada orangtua untuk membantu mengurangi rasa stres dan terpisah dari bayinya (Mok \& Leung, 2006 dalam Kearvell \& Grant, 2008).

Setiap orangtua dengan bayi yang sakit kritis memiliki kebutuhan prioritas yang berbeda-beda dan unik. Kebutuhan orangtua dipengaruhi seperti sosial ekonomi, tingkat pendidikan, lingkungan perawatan, diagnosis penyakit bayi, dan lain-lain 
Viva Medika: Jurnal Kesehatan, Kebidanan, dan Keperawatan, 11 (02), Maret 2019

Adiratna Sekar Siwi (Gambaran Kebutuhan Orangtua Dengan Bayi Yang Sakit kritis di RSUD

Prof.dr. Margono Soekarjo Purwokerto)

(Mundy, 2010 \& Chatzaki et al, hasil reliabilitasnya menggunakan 2012).

Cronbach's alpha menghasilkan nilai 0.94 (Mundy, 2010).

Data yang diperoleh dianalisis

\section{METODE PENELITIAN}

Penelitian ini merupakan studi deskriptif dengan pendekatan cross sectional. Penelitian ini melibatkan 70 responden, dengan menggunakan rumus Slovin. Teknik sampling yang digunakan dalam penelitian ini adalah non probability sampling, dengan consecutive sampling. Pengambilan data dilaksanakan pada bulan JuniJuli 2016 di RSUD Prof. Dr. Margono Soekarjo Purwokerto. Instrumen dalam penelitian ini adalah kuesioner NFNI (NICU Family Needs Inventory). Kuesioner NFNI berisi 56 pernyataan meliputi kebutuhan terhadap informasi, kepastian, kedekatan, kenyamanan dan dukungan. Kuesioner NFNI menggunakan sakal Likert dengan rentang skor $1-4$, dengan nilai $1=$ tidak penting, $2=$ cukup penting, $3=$ penting dan $4=$ sangat penting. Kuesioner NFNI sudah diuji validitas dan reliabilitas oleh Ward (2001), dengan menggunakan analisis univariat dan disajikan dalam bentuk rerata nilai masing-masing kebutuhan.

\section{HASIL DAN PEMBAHASAN}

Berikut hasil penghitungan rerata kebutuhan orangtua dengan bayi sakit kritis yang dirawat di NICU RSUD Prof. Dr. Margono Soekarjo Purwokerto

Tabel 1 Nilai Mean Kebutuhan Orangtua Dengan Bayi Sakit Kritis yang Dirawat Di NICU RSUD Prof. Dr. Margono Soekarjo Purwokerto Tahun $2016(n=70)$

\begin{tabular}{clcc}
\hline No & $\begin{array}{c}\text { Dimensi } \\
\text { Kebutuhan }\end{array}$ & Mean & $\begin{array}{c}\text { Standar } \\
\text { Deviasi }\end{array}$ \\
\hline 1 & Kedekatan & 3.54 & 0.38 \\
2 & Kepastian & 3.49 & 0.27 \\
3 & Kenyamanan & 3.25 & 0.40 \\
4 & Informasi & 3.24 & 0.37 \\
5 & Dukungan & 3.15 & 0.36 \\
\hline \multicolumn{4}{c}{ Pada tabel 1 menunjukkan bahwa }
\end{tabular}
kebutuhan sangat penting bagi orangtua adalah kebutuhan terhadap kedekatan dengan nilai mean $=3.54$ dan $\mathrm{SD}=0.38$. Nilai mean terendah terdapat pada dimensi kebutuhan 
Viva Medika: Jurnal Kesehatan, Kebidanan, dan Keperawatan, 11 (02), Maret 2019

Adiratna Sekar Siwi (Gambaran Kebutuhan Orangtua Dengan Bayi Yang Sakit kritis di RSUD

Prof.dr. Margono Soekarjo Purwokerto)

dukungan dengan nilai mean $=3.15$ dan $\mathrm{SD}=0.36$.

Penelitian ini menunjukkan bahwa orangtua lebih memprioritaskan kebutuhan terhadap kedekatan. Hal ini sesuai dengan budaya Jawa bahwa dalam kehidupannya ingin selalu berkumpul dengan anggota keluarganya. Selain itu, seorang ayah menggambarkan kedekatan dengan bayinya melalui kata-kata dan dengan melihat bayinya dari kejauhan. Ibu menggambarkan kedekatannya dengan kontak fisik (Latour et al, 2010).

Kondisi bayi yang harus dirawat di NICU mengakibatkan kontak fisik antara orangtua dan bayi menjadi sangat minim (Guillaume et al, 2013). Hal ini sesuai dengan kondisi di RSUD Prof. Dr. Margono Soekardjo Purwokerto, bahwa orangtua tidak diijinkan untuk melakukan kontak fisik saat jam kunjungan, jam kunjungan sangat dibatasi hanya pada pukul 11.30 s.d 12.30 dan 16.30 s.d 17.30 serta saat jam kunjungan orangtua hanya bisa melihat kondisi bayinya dari balik kaca jendela ruang perawatan bayi. Kunjungan yang dibatasi dapat mengurangi kontak serta kedekatan orangtua dengan bayinya, yang bisa mengakibatkan gangguan pertumbuhan dan perkembangan baik secara fisik atau emosional. Bayi merasakan kurangnya ikatan batin dan sentuhan dari orangtua. Jika bayi sudah dalam kondisi stabil dan alat bantu medis sebagian besar sudah terlepas, maka orangtua bisa mengunjungi bayinya serta dapat menggendongnya dengan diawasi perawat.

Kebutuhan untuk mengetahui perkembangan kondisi bayinya serta dapat menggendong atau memeluk bayinya merupakan hal yang dapat mengurangi tingkat kecemasan orangtua (Mundy, 2010). Sentuhan dari orangtua terhadap bayi, banyak memberikan manfaat kepada bayi. Menurut Mitchel \& Chaboyer (2010), sentuhan kepada bayi mampu meningkatkan kelancaran sirkulasi darah sehingga nutrisi dan oksigen dapat memenuhi kebutuhan sel serta merangsang hormon pertumbuhan bayi. Selain itu, sentuhan kepada bayi mampu menstimulasi saraf otak 
Viva Medika: Jurnal Kesehatan, Kebidanan, dan Keperawatan, 11 (02), Maret 2019

Adiratna Sekar Siwi (Gambaran Kebutuhan Orangtua Dengan Bayi Yang Sakit kritis di RSUD

Prof.dr. Margono Soekarjo Purwokerto)

terutama nervus vagus yang mampu meningkatkan produksi hormon pencernaan (gastrin dan insulin) sehingga dapat meningkatkan penyerapan nutrisi dan berat badan bayi.

Manfaat lain dari sentuhan orangtua kepada bayi, juga dapat dirasakan oleh orangtua bayi. Orangtua bisa mengelus, jika memungkinkan bisa menggendongnya. Hal tersebut mampu menurunkan hormon kortisol sehingga dapat menurunkan tingkat kecemasan orangtua. Disisi lain, orangtua yang mendampingi bayinya secara langsung dapat menumbuhkan ikatan kasih sayang serta merangsang pengeluaran ASI (Air Susu Ibu) (Bredemeyer et al, 2008).

Selama masa hospitalisasi, orangtua lebih mudah mengalami cemas dikarenakan terpisah dengan bayinya, kesempatan untuk berinteraksi sangat dibatasi, orangtua mengalami kesulitan dalam merawat bayinya, dimana hal tersebut dapat mengganggu kedekatan antara ibu dan bayi selama di NICU (Alkozei,
McMahon \& Lahav, 2014; Alves et al, 2016). Selain itu, bayi yang dirawat di NICU menggunakan alat medis sehingga mempersulit hubungan fisik antara orangtua dan bayi (Gooding, 2010).

Hasil penelitian Davidson (2009), kebutuhan terhadap kedekatan dengan pasien dan dapat mengunjungi pasien setiap waktu merupakan kebutuhan yang sangat penting, karena keluarga bisa mendapatkan informasi yang penting saat mengunjungi pasiennya. Penelitian lain yang serupa oleh MacAdam et al (2008) bahwa dengan mendampingi anggota keluarga yang sakit kritis, dapat melihat anggota keluarga yang sakit serta mendapatkan informasi yang terpercaya mengenai perkembangan kondisi.

Setelah kebutuhan terhadap kedekatan, kebutuhan selanjutnya yang dinyatakan sangat penting bagi orangtua adalah kebutuhan terhadap kepastian. Kebutuhan kepastian merupakan kebutuhan dimana orangtua percaya terhadap tenaga kesehatan yang merawat bayinya dengan penuh tanggung jawab, dapat 
Viva Medika: Jurnal Kesehatan, Kebidanan, dan Keperawatan, 11 (02), Maret 2019

Adiratna Sekar Siwi (Gambaran Kebutuhan Orangtua Dengan Bayi Yang Sakit kritis di RSUD

Prof.dr. Margono Soekarjo Purwokerto)

menjamin bayinya mendapatkan kenyamanan, pemenuhan nutrisi, mendapatkan kepastian kondisi bayinya terkait penyakitnya, prognosis bahkan terkait kemungkinan kematian serta memberikan harapan kepada keluarga terkait perbaikan kondisi (Abvali et al, 2015; Alves et al, 2016).

Orangtua mengharapkan mendapatkan informasi yang sejelasjelasnya atas kondisi perkembangan bayinya serta saat orangtua menanyakan suatu hal terkait kondisi bayinya mendapatkan jawaban yang sejujur-jujurnya dari tenaga kesehatan tanpa ada yang dirahasiakan sehingga dapat terjalin hubungan saling percaya antara orangtua dan tenaga kesehatan. Pemberian informasi yang diberikan kepada orangtua mampu meningkatkan kepercayaan terhadap tenaga kesehatan sehingga orangtua mempercayakan segala tindakan kepada bayinya tidak menimbulkan bahaya (Alves et al, 2016)

Kepercayaan yang tumbuh dalam diri orangtua dapat meningkatkan keyakinan bahwa bayinya mendapatkan perawatan yang tepat.
Hal tersebut dapat diwujudkan salah satunya dengan menghadirkan orangtua saat dilakukan tindakan agar orangtua merasa tenang dan yakin serta dapat mengetahui secara langsung konsisi bayinya (Mundy, 2010). Dari hasil observasi bahwa, orangtua yang merasakan cemas dan senantiasa menanyakan kondisi kesehatan bayinya kepada tenaga kesehatan (perawat atau dokter). Perawat atau dokter mencoba memberikan jawaban yang membangun rasa optimis, harapan orangtua agar proses perawatan bisa maksimal serta membantu mengatasi kecemasan yang dialami oleh orangtua.

Kebutuhan selanjutnya yang dirasa penting bagi orangtua adalah kebutuhan terhadap kenyamanan. Kebutuhan terhadap kenyamanan merupakan kebutuhan terhadap kenyamanan pribadi seperti tersedianya fasilitas di sekitar ruang perawatan (kamar mandi, tempat beribadah, ruang menyusui yang nyaman, ruang tunggu serta ruang konsultasi). Menurut Nicholas (2006), 
Viva Medika: Jurnal Kesehatan, Kebidanan, dan Keperawatan, 11 (02), Maret 2019

Adiratna Sekar Siwi (Gambaran Kebutuhan Orangtua Dengan Bayi Yang Sakit kritis di RSUD

Prof.dr. Margono Soekarjo Purwokerto)

bahwa lingkungan perawatan yang nyaman merupakan salah satu kebutuhan yang dibutuhkan oleh orangtua selama menunggu bayinya yang sedang menjalani perawatan. Orangtua yang berada pada lingkungan yang nyaman serta mendapatkan perlakuan yang positif dari tenaga kesehatan (perawat, dokter dan staf kesehatan lainnya) mampu mengatasi tingkat stres atau kecemasan yang dialami oleh orangtua (Sikorova \& Kucova, 2012).

Dari hasil observasi peneliti, bahwa di ruang perawatan bayi tersedia ruang menyusui, ruang kangoro, serta ruang konsultasi yang nyaman. Tersedianya ruang menyusui yang nyaman dan menjaga privacy orangtua, maka dengan nyaman orangtua dapat memompa ASInya sebagai nutrisi yang diberikan kepada bayinya. Ruang konsultasi, jika orangtua sewaktu-waktu ingin mengetahui kondisi kesehatan bayinya maka bisa melakukan perjanjian dengan dokter penanggung jawab. Ruang khusus konsultasi memudahkan orangtua bayi menyampaikan hal-hal yang terkait dengan kondisi bayinya.

Kebutuhan selanjutnya adalah kebutuhan terhadap informasi. Kebutuhan terhadap informasi merupakan kebutuhan dimana orangtua mendapatkan informasi yang sejelas-jelasnya dari tenaga kesehatan, perawat memperkenalkan anggota timnya yang merawat bayinya, menjelaskan apa yang menjadi pertanyaan keluarga terkait kondisi bayinya, memberikan penjelasan mengenai rencana tindakan selama masa perawatan, menjelaskan prosedur tindakan dan alasan yang akan dilakukan serta dapat menyampaikan informasi atau memperantarai komunikasi antara dokter dan keluarga pasien (Neves et al, 2009; Abvali et al, 2015).

Dalam penelitian Neves et al (2009), bahwa kebutuhan informasi merupakan kebutuhan yang dibutuhkan oleh orangtua selama menunggu bayinya di NICU. Hasil penelitian lainnya oleh Alves et al (2016), bahwa orangtua melaporkan kebutuhan informasi sangat 
Viva Medika: Jurnal Kesehatan, Kebidanan, dan Keperawatan, 11 (02), Maret 2019

Adiratna Sekar Siwi (Gambaran Kebutuhan Orangtua Dengan Bayi Yang Sakit kritis di RSUD

Prof.dr. Margono Soekarjo Purwokerto)

dibutuhkan karena informasi yang disampaikan oleh tenaga kesehatan dapat membantu meningkatkan pengetahuan tentang kondisi perkembangan bayinya. Penelitian yang serupa bahwa orangtua dengan bayi sakit kritis yang dirawat di NICU sangat membutuhkan informasi yang jelas dan lengkap dari tenaga kesehatan mengenai perkembangan kondisi bayinya (Mundy, 2010).

Didukung penelitian lain oleh Aldridge (2005) menyatakan bahwa beberapa orangtua dari bayi yang dirawat di ruang intensif membutuhkan informasi yang terdiri dari perkembangan penyakit, mengetahui prognosis penyakit, mendapatkan jawaban yang jujur mengenai bayinya, mengetahui peralatan yang digunakan untuk perawatan bayinya. Shudy et al (2006) kebutuhan orangtua saat bayi dirawat di intensif adalah mengetahui yang salah dengan bayinya dan menginformasikan perkembangannya. Chulay dan Burns (2006) menyediakan informasi persiapan bagi pasien dan keluarga sangat membantu dalam mengontrol kecemasan.

Perawat yang memberikan asuhan keperawatan selama 24 jam mampu menjelaskan kondisi yang terjadi pada bayinya, karena informasi harian yang diberikan oleh perawat jauh lebih penting. Selain informasi yang jelas, lengkap dan jujur, komunikasi perawat atau dokter sebaiknya mudah dipahami, diterima oleh orangtua. Orangtua mengharapkan perawat dapat memberikan informasi secara rutin, tanpa diminta dan tidak menakut-nakuti sehingga orangtua tidak mengalami kecemasan. Didukung oleh penelitian oleh Holditch-Davis \& Miles (2000), bahwa tenaga kesehatan mempunyai peran dalam menurunkan kecemasan orangtua yaitu salah satunya dengan menjaga komunikasi dengan orangtua dan menyakinkan dirinya melakukan yang terbaik selama merawat bayinya. Selain itu, perawat juga bisa memfasilitasi komunikasi antara orangtua dan dokter (Cleveland, 2008). Beberapa orangtua merasa dirinya tidak bisa memahami 
Viva Medika: Jurnal Kesehatan, Kebidanan, dan Keperawatan, 11 (02), Maret 2019

Adiratna Sekar Siwi (Gambaran Kebutuhan Orangtua Dengan Bayi Yang Sakit kritis di RSUD

Prof.dr. Margono Soekarjo Purwokerto)

informasi yang disampaikan oleh dokter, dan segan atau takut untuk menanyakan kembali pertanyaannya takut dibilang cerewet (Yang, 2008). Padahal informasi yang kurang jelas atau yang belum dipahami oleh orangtua dapat menimbulkan stres atau cemas (McAdam \& Puntillo, 2009 \& Frank et al, 2011).

Dari hasil observasi, bahwa penyediaan media kesehatan (leaflet atau poster) masih kurang. Pelaksanaan pendidikan kesehatan biasanya diberikan oleh mahasiswa yang sedang praktek di ruang NICU. Kemudian orangtua jika menginginkan informasi bisa menanyakan kepada perawat atau melakukan perjanjian untuk konsultasi dengan dokter. Selama ini, pemberian informasi sudah terfasilitasi dari ruang perawatan bayi, hanya saja pemberian informasi yang sifatnya harian kepada orangtua bayi belum terlaksana secara maksimal.

Kebutuhan terakhir adalah kebutuhan terhadap dukungan. Kebutuhan terhadap dukungan merupakan sumber, sistem yang dibutuhkan oleh orangtua agar mampu menerima kondisi yang dialami saat ini. Dukungan yang diharapkan oleh orangtua antara lain mengekspresikan emosionalnya, mendapatkan perhatian, finansial serta spiritual.

Kebutuhan terhadap dukungan sangat diperlukan oleh orangtua untuk menciptakan koping yang adaptif (Feldman et al 1999 dalam Padovani et al, 2004). Hasil penelitian oleh Ward (2001); Nicholas (2006) \& Mundy (2011) menyatakan orangtua membutuhkan dukungan dari sesama orangtua yang mempunyai bayi sakit kritis yang sedang menjalani perawatan di ruang perawatan bayi. Dukungan yang diberikan sesama orangtua bisa dalam hal berbagi pengalaman, memotivasi dan saling menguatkan.

Selain pemberian dukungan berupa perhatian, pemenuhan kebutuhan spiritual diharapkan mampu mengembalikan keyakinan, memenuhi kewajiban agama serta dapat meningkatkan hubungan antara dirinya dengan sang Pencipta (Hamid, 2010). Keluarga membutuhkan tempat 
Viva Medika: Jurnal Kesehatan, Kebidanan, dan Keperawatan, 11 (02), Maret 2019

Adiratna Sekar Siwi (Gambaran Kebutuhan Orangtua Dengan Bayi Yang Sakit kritis di RSUD

Prof.dr. Margono Soekarjo Purwokerto)

ibadah yang dekat dengan tempat perawatan karena pada kondisi yang dialami saat ini, keyakinan spiritual dan keinginan untuk berdoa lebih tinggi dari biasa yang dilakukan. Dukungan psikoreligius tidak kalah pentingnya dengan psikoterapi psikiatrik, karena mengandug kekuatan spiritual yang mampu membangkitkan rasa percaya diri dan optimisme. Perasaan percaya diri dan optimisme merupakan hal yang sangat pokok selama masa penyembuhan suatu penyakit disamping tindakan medis lainnya (Hawari, 2004).

\section{SIMPULAN DAN SARAN}

\section{Simpulan}

Kebutuhan orangtua dengan bayi sakit kritis di ruang perawatan bayi adalah kebutuhan terhadap kedekatan, kepastian, kenyamanan, informasi dan kebutuhan yang terakhir adalah adalah kebutuhan terhadap dukungan.

\section{Saran}

Perawat perlu mengkaji kebutuhan setiap orangtua, karena kebutuhan setiap orangtua berbeda-beda. Hasil penelitian ini bisa menjadi sebagai bahan dasar untuk membuat kebijakan atau Standar Prosedural Operasional untuk membuat sebuah intervensi. Sebagai contoh kebijakan yang perlu dipertimbangkan adalah memberikan kesempatan kepada orangtua untuk menunggu serta keterlibatan selama masa perawatan bayi di NICU sehingga mampu meningkatkan kualitas pelayanan, kepuasan keluarga serta mewujudkan Family Center Care (FCC).

\section{DAFTAR PUSTAKA}

Abvali, A., Peyrovi, H., Moghaddam, O.M., \& Gohari, M. (2015). Effect of support program on satisfaction of family members of ICU patients. Clien-Centered Nursing Care, 1 (1), 29-35

Alkozei, A., McMahon, E., \& Lahav, A. (2014). Stress level and depressive symptomps in NICU mothers in the early postpartum period. The journal maternal-fetl \& neonatal medicine. DOI: 10.3109/14767058.2014.942626

Alves, E., Severo, M., Amiron, M., Grande, C \& Silva, S. (2016). A short form of the neonatal intensive care unit family needs inventory. $J$ Pediatr, 92 (1), 73-80. 
Viva Medika: Jurnal Kesehatan, Kebidanan, dan Keperawatan, 11 (02), Maret 2019

Adiratna Sekar Siwi (Gambaran Kebutuhan Orangtua Dengan Bayi Yang Sakit kritis di RSUD

Prof.dr. Margono Soekarjo Purwokerto)

Bredemeyer, S., Reid, S., Polveriono, J \& Wocadlo, C. (2008). Implementation an evaluation of an individualized developmental care program in a Neonatal Intensive Care Unit. Journal Compilation, 13 (4), 281-296

Chatzaki, M. Klimathianaki, M., Anastasaki, M., Chatzakis, G., Apostolakou, E., \& Georgopoulos., D. (2011). Defining the needs of ICU patient families in a Suburban/ Rural Greek Population: a prospective cohort study. Journal of Clinical Nursing, 21, 1831-1839. DOI: $\quad 10.1111 / j .1365-$ 2702.2011.04022.x.

Chulay, M. \& Burns, S.M. (2006). $A A C N$ essentials of critical care. United States America: McGrawHill Company

Cleveland, L.M. (2008). Parenting in the Neonatal Intensive Care Unit the association of women's health, obstetric and neonatal nurses. JOGNN, 37 (6), 666-691. DOI: 10.1111/j.1552-6909.2008.00288.x

Davidson, J.E., Powers, K. Hedayat, K.M., Tieszen, M., Kon, A.A., Shepard, E. \& Spuhler, V. (2007). Clinical practice guidelines for support of the families in the patient-centered intensive care unit: American College of Critical care Medicine Task Force 2004-2005. Crit Care Med, 35 (2). DOI: 10/1097/01.CCM.0000254067.146 07.EB
Fenwick, J., Barclay, L., \& Schmied, V. (2008). Craving closeness: A grounded theory analysis of women's experiences of mothering in the Special Care Nursery. Women and Birth, 21 (2), 71-85

Guillaume, S., Michelin, N., Amrani, E., Benier, B., Durrmeyer, X., Lescure, S., \& Bony, C. (2013). Parent's expectations of staff in the early bonding process with their premature babies in the intensive care setting: A qualitative multicenter study with 60 parents. BMC Pediatrics, 13 (18)

Hendrawati, S. (2015). Analisis kebutuhan orangtua dan faktorfaktor yang memengaruhinya untuk mengaplikasikan Family Centered Care di ruang NICU Rumah Sakit Pemerintah Wilayah Bandung Raya. Tesis: Fakultas Keperawatan Universitas Padjadjaran Bandung

Holditch-Davis, D \& Miles, M.S. (2000). Mother's stories about their experiences in the neonatala intensive care unit. The Journal of Neonatal Nursing, 19 (3), 13-21

Kearvell, H. \& Grant, J. (2008). Getting connected: How nurses can support mother/ infant attachment in the Neonatal Intensive Care Unit. Australian Journal of Advanced Nursing, 23 (3)

Lee, S.C. (2008). Taiwanese women's experiences of becoming a mother to a very-low-birth-weight preterminfant: A grounded theory 
Viva Medika: Jurnal Kesehatan, Kebidanan, dan Keperawatan, 11 (02), Maret 2019

Adiratna Sekar Siwi (Gambaran Kebutuhan Orangtua Dengan Bayi Yang Sakit kritis di RSUD

Prof.dr. Margono Soekarjo Purwokerto)

study. International Journal of Nursing Studies, 4, 326-327

McAdam, J.L., Arai, S \& Puntillo, K.A. (2008). Unrecognized contributions of families in the Intensive Care Unit. Intensive Care Med, 34, 1097-1101. DOI: 10.1007/s00134-008-1066-z

Mitchel, M.M \& Chaboyer, W. (2010). Family centered care a way to connect patients, families and nurses in critical care: A qualitative study using telephone interviews. Intensive and Critical Care Nursing, 26, 154-160. DOI: $10.1016 / \mathrm{j} / \mathrm{iccn} .2010 .06 .004$

Mok, E \& Leung, S. (2006). Nurses as providers of support for mothers of premature infants. Children and Families, 15, 726-734

Mundy,C.A. (2010). Assessment of family needs in neonatal intensive care units. American Journal of Critical Care, 19 (2), 156-163

Neves et al. (2009). Analysis of family satisfaction in intensive care unit. Rev Bras Ter Intensive, 21 (1), 3237

Padovani, F.H., Linhares, M.B.M., Carvalho, A.E.V., Duarte, G., \& Martinez, F.E. (2004). Anxiety and depression symptoms assessment in pre-term neonates mother's during and after hospitalization in neonatal intensive care unit. Rev Bras Psiqulatr, 26 (4), 251-254
Sikorova, L \& Kucova, J. (2012). The needs of mothers to newborns hospitalized in Intensive Care Unit. Biomed, 156 (4), 330-336

Supartini, Y. (2004). Buku ajar konsep dasar keperawatan anak. Jakarta: EGC 